\title{
Indoor Dust Metal Loadings: A Human Health Risk Assessment
}

\author{
F. Barrio-Parra ${ }^{1}$ E. De Miguel ${ }^{1} \cdot$ S. Lázaro-Navas ${ }^{1} \cdot$ A. Gómez $^{1}$. \\ M. Izquierdo ${ }^{1}$
}

\begin{abstract}
In order to characterize the influence of environmental factors in dust metal loadings inside homes in an urban environment and to evaluate the associated potential health risks, samples of settled indoor dust from 10 apartments in the urban area of Madrid (Spain) were collected with wet wipes. $\mathrm{Cd}, \mathrm{Cr}, \mathrm{Cu}, \mathrm{Pb}, \mathrm{Zn}, \mathrm{Ni}$, and $\mathrm{Mn}$ loads were determined by Atomic Absorption Spectroscopy (AAS) after a $\mathrm{HNO}_{3}+\mathrm{H}_{2} \mathrm{O}_{2}$ digestion. The environmental factors evaluated were load distribution between rooms, number of residents, presence of smokers, traffic intensity, apartment elevation, and frequency of house cleaning. Tukey's range test and stepwise multiple linear regression analysis revealed that metal dust loadings present two prevailing origins: (1) They present higher loadings in the entry hall, which suggest that dust is tracked indoors adhered to footwear and clothing and (2) they arise from tobacco smoking. Significant correlations were also observed between metal loadings and traffic intensity $(\mathrm{Cr})$, number of residents $(\mathrm{Cr}, \mathrm{Pb}$, and $\mathrm{Cu}$ ), number of days between cleaning $(\mathrm{Ni})$, and flat height $(\mathrm{Mn})$. A human health risk assessment considering a mechanistic hand-tomouth model for dust ingestion and dermal absorption revealed that urban children are not expected to develop adverse health effects from exposure to trace elements in household dust. The contribution of this exposure scenario to the overall received dose should be included when assessing the background exposure of children to trace elements. A more precise assessment should attempt to
\end{abstract}

$\bowtie$ F. Barrio-Parra

fernando.barrio@upm.es

1 Environmental Geochemistry Research and Engineering Laboratory, Universidad Politécnica de Madrid, Alenza 4, 28003 Madrid, Spain reduce the significant uncertainty of the risk model output associated with estimates of exposure variables, deposition rates, and metal bioaccessibility.

Keywords Indoor dust - Metal loadings - Wipe sampling • Human health risk assessment · Urban environment

\section{Introduction}

Over the past decades, there has been an increasing concern regarding exposure to indoor contaminants given the large amount of time that people spend indoors, i.e., inside homes, offices, and schools: $88 \%$ of the day for adults and 71-79\% of the day for children (USEPA 1997). One of the most important sources of indoor contaminants is settled and resuspended dust. Indoor dust is a complex mixture of organic and inorganic particles (Fergusson and Kim 1991; Lioy et al. 2002; Kurt-Karakus 2012) that have settled onto objects, surfaces, floors, and carpeting (USEPA 2008), and acts as a reservoir of contaminants (Butte and Heinzow 2002). The composition of settled house dust can differ considerably between geographic locations (industrial or mining zones. rural vs urban areas, etc.) and between rooms of a given house (Khoder et al. 2010). House dust particles containing metals can be generated indoors or they can be tracked inside from outdoors. Soil and street dust are carried indoors by residents (adhering to footwear) and their pets. The metal contribution of soil to dust loadings is between 30 and 40\% (Butte and Heinzow 2002; Ibanez et al. 2010). The other main migration pathway of metals into homes is the infiltration of outdoor air containing suspended particulate matter (Thatcher and Layton 1995; Hunt et al. 2006). Among indoor sources of contaminants in household dust are cleaning products, paint 
chips, cooking fumes, cigarette smoking, construction, furnishing and carpet materials, emissions from heating systems, etc. (Lisiewicz et al. 2000; Khoder et al. 2010; Mcdonald et al. 2010). Establishing relationships between trace elements loads in indoor dust and factors that might influence them is a difficult task that has not been satisfactorily accomplished yet.

House dust has been identified as an important source of exposure to trace elements, particularly for children (Lisiewicz et al. 2000; USEPA 2008), through direct accidental ingestion, inhalation of resuspended dust particles, and dermal absorption (Zota et al. 2011). At high concentrations, many of these trace elements are toxic and are potential cofactors initiators or promoters in diseases, notably cardiovascular disorders and cancer (Tong and Lam 1998). For this reason, the study of this exposure medium is important to assess its potential direct impact on human health and its relative contribution (together with diet, outdoor soil and dust, and atmospheric aerosol) to the trace element dose received by children in urban environments.

Younger children are more vulnerable than adults to heavy metal exposure and poisoning because of their earlier development stage and child-specific behaviors. The maximal brain growth and differentiation take place in the first few years of life, when gastrointestinal absorption of contaminants in children is higher than in adults: approximately $50 \%$, as opposed to $8 \%$ (Tong and Lam 1998). Children may ingest significant quantities of dust due to their frequent hand-to-mouth activity (touching and mouthing of various dust-contaminated objects), crawling on the floor (USEPA 2008; Zhu et al. 2015), and having higher inhalation rates per unit of body mass than adults (Zota et al. 2011). In addition, the tolerance of children to toxins is lower than in adults, exacerbating the potential for adverse health effects (Kurt-Karakus 2012).

Metal levels in dust cannot be predicted from soil concentrations alone which makes it necessary to perform local studies to asses them (Ibanez et al. 2010). A large number of investigations have reported metal concentrations in indoor dust (Tong and Lam 1998; Lisiewicz et al. 2000; Tong and Lam 2000; Chattopadhyay et al. 2003; Turner and Hefzi 2010; Zota et al. 2011; Kurt-Karakus 2012). A much lower number of studies, however, have attempted to measure metal loadings (Khoder et al. 2010; Rasmussen et al. 2013) and those that have employed a wipe sampling method to determine the distribution of metal loadings between rooms have focused on a very limited number of elements (Mcdonald 2010; Mcdonald et al. 2010).

Following what has been discussed above, the main objectives of this study are (1) to evaluate the influence of different factors (smoking, traffic intensity, number of residents, apartment elevation, and frequency of house cleaning) in the metal loadings of indoor dust in an urban environment and (2) to characterize the associated risk to human health.

\section{Materials and Methods}

\section{Study Area and Sampling Locations}

Madrid, which is located in the center of the Iberian Peninsula, is the capital city of Spain. This urban area extends over $600 \mathrm{~km}^{2}$ and has a population of approximately 3 million inhabitants (INE 2014). The climate in the Madrid region is Continental Mediterranean, with moderately cold winters and hot summers (annual average temperature $15^{\circ} \mathrm{C}$ ), and relatively dry with an average precipitation of $400 \mathrm{~mm} \mathrm{year}^{-1}$ (AEMET 2014). The number of motor vehicles in Madrid is estimated at 4 million (DGT 2013).

The 10 apartments included in the study were selected in order to maximize the variability of those factors anticipated to control metal loadings in dust: presence of smokers, traffic intensity, apartment elevation, and frequency of house cleaning. Traffic intensity (vehicles per day) was obtained from a municipal database (Madrid Council 2013).

All homes, except one, were located within the M-40 ring road where population density and traffic volume are higher than in peripheral districts (Fig. 1). A total of 40 samples were collected in these apartments during the

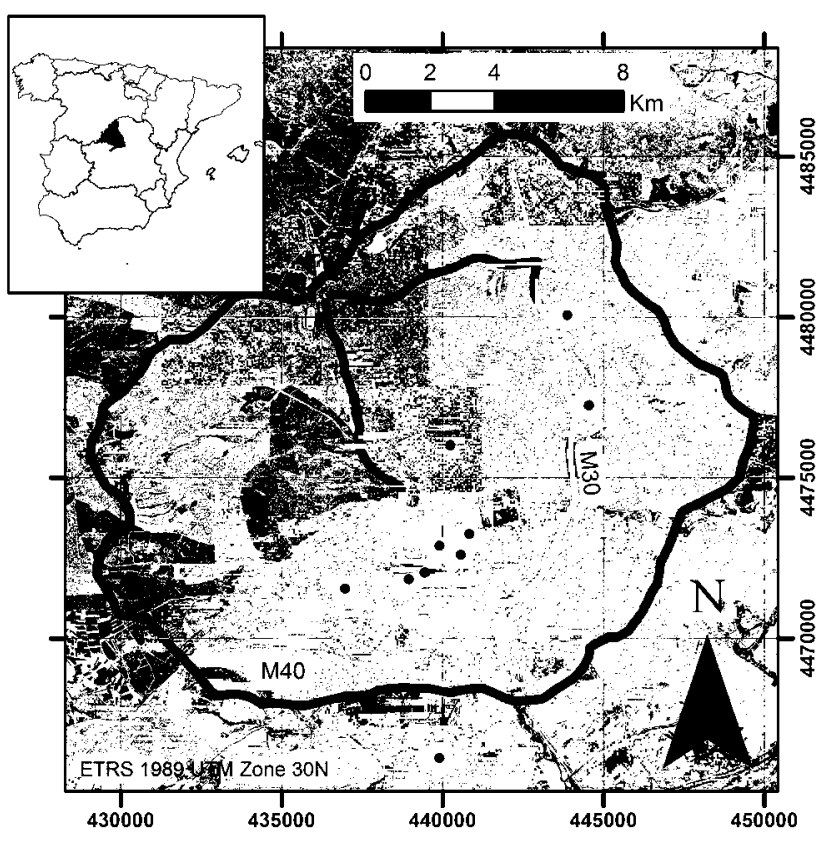

Fig. 1 Location of sampled homes (dots) 
April-May period of 2015. Weather during this season is predominantly mild, so heating and air conditioning systems were not in use and have not been taken into account in the interpretation of results.

\section{Sample Collection and Analysis}

Samples of indoor dust were collected with wet wipes that simulate the contact of children's hands with surfaces (Yiin et al. 2002). This method also allows to asses room-toroom variability and the identification of sources based on the activities conducted in the different rooms sampled (Mcdonald et al. 2010). Furthermore, metal recovery using wet wipes on non-carpeted floors was higher than that obtained using a vacuum cleaner method under the same conditions (Butte and Heinzow 2002).

Four samples were collected in each apartment: one in the entry hall, one in the living room, one in the kitchen, and the last one in a bedroom. A non-carpeted area (hard surface) of $1 \mathrm{~m}^{2}$ in the middle of each room was delimitated and settled dust was sampled according to the USEPA standard procedure with wet wipes ("Ghost Wipes ${ }^{(\mathbb{B}) ") ~ f o r ~}$ lead (USEPA 1995). The collected wipes were placed into labeled 50-mL polypropylene tubes (digiPREP ${ }^{\mathrm{TM}}$ digestion tube, SPC science) and preserved inside sealed plastic bags for transport to the laboratory.

The analytical method employed in this study was based on a modification of the USEPA's protocol for wipe samples (USEPA 1996a), which consists in an acid digestion with concentrated $\mathrm{HNO}_{3}$ and $30 \% \mathrm{H}_{2} \mathrm{O}_{2}$. The modifications included (1) heating of samples at $110^{\circ} \mathrm{C}$, (2) use of a digiPREP ${ }^{\mathrm{TM}}$ heating block system, and (3) dilution of the final volume with MilliQ water to $50 \mathrm{~mL}$. Instrumental analysis was conducted with a graphite furnace atomic absorption spectrometer (GF-AAS, Analytik Jena model contrAA ${ }^{(\mathbb{B}} 700$ ).

From each apartment, one field blank and one field duplicate were collected. The field blank wipe was exposed to all handling procedures used for samples except that no surface was wiped. The room from which the duplicate was collected rotated among homes. A total of 10 field blank wipes and 10 duplicate wipes were collected. During the analyses, two certified sandy soil reference materials were included (WEPAL ISE 967 and ISE 987). Except Cd, all mean recoveries of these materials were within $\pm 10 \%$ of the certified value. $\mathrm{Cd}$ data were corrected according to its recovery rate.

Detection limits were $0.012 \mu \mathrm{g} / \mathrm{m}^{2}$ for $\mathrm{Cd}, 0.122 \mu \mathrm{g} / \mathrm{m}^{2}$ for $\mathrm{Cr}, 0.089 \mu \mathrm{g} / \mathrm{m}^{2}$ for $\mathrm{Pb}, 1.060 \mu \mathrm{g} / \mathrm{m}^{2}$ for $\mathrm{Cu}, 2.940 \mu \mathrm{g}$ / $\mathrm{m}^{2}$ for $\mathrm{Zn}, 0.321 \mu \mathrm{g} / \mathrm{m}^{2}$ for $\mathrm{Ni}$, and $0.044 \mu \mathrm{g} / \mathrm{m}^{2}$ for $\mathrm{Mn}$.

\section{Data Analysis}

Metal loadings obtained by wipe sampling are expressed in $\mu \mathrm{g}$ metal $/ \mathrm{m}^{2}$ floor. In order to compare these results with those of most studies of indoor dust, concentration values ( $\mu \mathrm{g}$ metal $/ \mathrm{kg}$ dust) reported elsewhere were transformed into loadings using an average dust deposition value \pm SD $\left(0.077 \pm 0.061 \mathrm{~g} / \mathrm{m}^{2} \cdot\right.$ week $)$, established with data from previous investigations (Thatcher and Layton 1995; Edwards et al. 1998; Rasmussen et al. 2013).

$\mathrm{R}$ studio (version 2.14.1) was used for the statistical analyses. Outliers, data higher than $Q_{3}+1.5 \times$ ( $Q_{3}-Q_{1}$ ), where $Q_{1}$ and $Q_{3}$ denote the first and the third quartile, respectively, were detected and removed before performing the statistical tests. Kolmogorov-Smirnov tests were carried out to check data distributions. Pearson correlation coefficients $(R)$ were determined to assess the relationships between elements. Tukey's range tests and stepwise multiple linear regression analysis were used to identify which of the considered ambient factors were the best predictors of the metal loadings and to assess their interrelationships.

\section{Human Health Risk Assessment (HHRA)}

Exposure of children to indoor dust can occur through three main pathways: ingestion of particles, dermal absorption of trace elements in particles adhered to exposed skin, and inhalation of resuspended particles. The contribution of inhalation to the overall dose received by children at home seems to be much lower than that of ingestion and dermal absorption (De Miguel et al. 2007; Turner 2011; Hassan 2012; Kurt-Karakus 2012), and only the latter two have been included in the risk assessment model. The exposed population was divided in five age groups: 0-6, 6-12 months, 1-2, 2-6 years, and an aggregate individual (0-6 years old).

The dose $\left(\mathrm{mg} \mathrm{kg}^{-1}\right.$ day $\left.^{-1}\right)$ received through ingestion $\left(D_{\text {ingestion }}\right)$ and dermal contact $\left(D_{\text {dermal }}\right)$ was calculated using Eqs. (1) and (2) adapted from the US Environmental Protection Agency (USEPA 1996b). The specific parameters used in these equations are shown in Table 1. Dust ingestion rates, DIG $\left(\mathrm{m}^{2} / \mathrm{day}\right.$ ), were taken from (Wilson et al. 2013 ; 2015) who established them using a mechanistic hand-to-mouth model. We choose the 95 th percentile of the estimates of DIG based on $100 \%$ hard surfaces for the risk assessment, except for the 0-6 months age group, for which it has been chosen the DIG based on $100 \%$ soft surfaces in agreement with Wilson et al. (2015).

$D_{\text {ingestion }}=\frac{L \times D I G \times E F \times E D}{B W \times A T} \times 10^{-3}$ 
Table 1 Parameters and exposure factors used in the risk assessment model

\begin{tabular}{|c|c|c|c|c|c|c|c|}
\hline \multirow[t]{2}{*}{ Parameter/exposure factor } & & \multicolumn{5}{|l|}{ Age groups } & \multirow[t]{2}{*}{ Reference } \\
\hline & & $0-6$ months & 6-12 months & $1-2$ years & $2-6$ years & $0-6$ years & \\
\hline Dust Ingestion rate & $\operatorname{DIG}\left(\mathrm{m}^{2} /\right.$ day $)$ & 0.088 & 0.34 & 0.34 & 0.29 & 0.286 & (Wilson et al. 2015) \\
\hline Exposed skin area ${ }^{a}$ & $\mathrm{SA}\left(\mathrm{cm}^{2}\right)$ & 1419 & 1935 & 2279 & 2945 & 2800 & (USEPA 2004. 2011) \\
\hline Average body weight & BW $(\mathrm{kg})$ & 6 & 9.2 & 11.4 & 16.2 & 15 & \\
\hline Exposure duration & $\mathrm{ED}$ (years) & 0.5 & 0.5 & 1 & 4 & 6 & \\
\hline Skin adherence factor & $\mathrm{SL}\left(\mathrm{mg} / \mathrm{cm}^{2} \cdot \mathrm{day}\right)$ & 0.2 & & & & & (USEPA 2002) \\
\hline Dermal absorption factor & ABS & $0.001^{\mathrm{b}}$ & & & & & (ICMM 2007) \\
\hline \multirow[t]{2}{*}{ Averaging time } & AT (days) & \multicolumn{5}{|c|}{$\mathrm{ED} \times 365$ (Non-carcinogenic) } & (USEPA 2011) \\
\hline & & \multicolumn{5}{|c|}{$78 \times 365$ (Carcinogenic) } & \\
\hline
\end{tabular}

a The exposed skin area includes hands, head, forearms, lower legs, and feet (43\% of the total)

${ }^{\mathrm{b}} \mathrm{Zn}$ is an exception (ABS $\left.=0.002\right)(\mathrm{ICMM} 2007)$

$$
\begin{aligned}
& D_{\text {dermal }}=\frac{C \times \mathrm{SL} \times \mathrm{SA} \times \mathrm{ABS} \times \mathrm{EF} \times \mathrm{ED}}{\mathrm{BW} \times \mathrm{AT}} \\
& \quad \times 10^{-6} .
\end{aligned}
$$

The trace element in indoor dust load, $L\left(\mu \mathrm{g} / \mathrm{m}^{2}\right)$, and concentration, C $\left(\mathrm{mg} \mathrm{kg}^{-1}\right)$ ("Data Analysis" section), which are the "exposure point load/concentration," were taken to be the upper limit of the $95 \%$ confidence interval for the mean (95\% UCL). In this study, the 95\% UCL was calculated with ProUCL 5.0 software (USEPA 2013).

The doses calculated with Eqs. (1) and (2) for each element and exposure pathway were subsequently divided by the corresponding Reference Dose to yield a hazard quotient, HQ (or non-cancer risk) (Eq. 3), whereas for carcinogens the dose was multiplied by the corresponding slope factor to produce a level of cancer risk (Eq. 4). Toxicity values used in this analysis were taken from USEPA's IRIS (Integrated Risk Information System) and from CalEPA (The California Environmental Protection Agency). Toxicity values for dermal absorption were calculated multiplying the oral reference doses (Eq. 5) and dividing the slope factors (Eq. 6) by their respective gastrointestinal absorption factors $\left(\mathrm{ABS}_{\mathrm{GI}}\right.$ ), to yield the corresponding dermal values. Chronic reference doses were used as conservative proxies for their sub-chronic toxicity values.

$$
\begin{aligned}
& \mathrm{HQ}=\frac{D}{R f D} \\
& \text { Risk }=D \times S F \\
& R f D_{\mathrm{ABS}}=R f D_{\mathrm{o}} \cdot A B S_{\mathrm{GI}} \\
& S F_{\mathrm{ABS}}=\frac{S F_{\mathrm{o}}}{\mathrm{ABS}_{\mathrm{GI}}} .
\end{aligned}
$$

\section{Results and Discussion \\ Influence of Environmental Factors}

Household dust metal loadings in the urban area of Madrid are summarized in Table 2. In overall terms, $\mathrm{Zn}$ showed the highest mean loading, followed by $\mathrm{Cu}, \mathrm{Mn}, \mathrm{Pb}, \mathrm{Ni}, \mathrm{Cr}$, and $\mathrm{Cd} . \mathrm{Cu}$ and $\mathrm{Pb}$ presented the highest coefficients of variation $(\mathrm{CV})$, while $\mathrm{Cd}, \mathrm{Cr}$, and $\mathrm{Mn}$ loadings were more homogeneous. The average indoor dust $\mathrm{Pb}$ loading in Madrid was below the regulatory value of $40 \mu \mathrm{g} / \mathrm{ft}^{2}$ $\left(430 \mu \mathrm{g} / \mathrm{m}^{2}\right.$ ) established by the USEPA (USEPA 2001).

A comparison with metal loadings obtained in other regions of the world is shown in Table 3. Since only a few studies of metal loadings have been previously undertaken (Khoder et al. 2010; Glorennec et al. 2012; Rasmussen et al. 2013; Lucas et al. 2014), metal concentrations ( $\mu \mathrm{g} / \mathrm{g})$ reported in studies that have applied vacuum sampling, hand brushing, or similar sampling techniques (Al-rajhl and Madany 1996; Lisiewicz et al. 2000; Tong and Lam 2000; Chattopadhyay et al. 2003; Turner and Simmonds 2006; Kurt-Karakus 2012) have been converted to load units $\left(\mu \mathrm{g} / \mathrm{m}^{2}\right)$ using a deposition value of $0.077 \mathrm{~g} / \mathrm{m}^{2}$ week, as explained in "Data Analysis" section. In agreement with the results of this study, $\mathrm{Zn}$ is generally the element with the highest loading, and $\mathrm{Cd}$ the lowest. It is noteworthy that $\mathrm{Cu}$ loadings were higher in Madrid than those reported for other regions. On the other hand, $\mathrm{Cr}$ and $\mathrm{Pb}$ loadings were below the levels found in most other locations.

A Pearson correlation analysis (Table 4) revealed that correlations between loadings of most metals included in the study were significant, suggesting common indoor and outdoor sources.

Potential differences between rooms were explored by means of a Tukey's range test with log-transformed data. 
Table 2 Metal loadings $(\mu \mathrm{g} /$ $\mathrm{m}^{2}$ ) in indoor dust samples in Madrid

\begin{tabular}{llllllll}
\hline & $\mathrm{Cd}$ & $\mathrm{Cr}$ & $\mathrm{Pb}$ & $\mathrm{Cu}$ & $\mathrm{Zn}$ & $\mathrm{Ni}$ & $\mathrm{Mn}$ \\
\hline Mean & 0.05 & 2.11 & 5.49 & 64.00 & 141.61 & 2.92 & 8.28 \\
$\mathrm{SD}$ & 0.03 & 1.47 & 9.56 & 136.68 & 161.47 & 3.03 & 6.71 \\
Median & 0.05 & 1.65 & 1.78 & 15.85 & 87.66 & 1.94 & 6.18 \\
Min & 0.02 & 0.72 & 0.19 & 2.12 & 6.48 & 0.36 & 0.58 \\
Max & 0.15 & 7.65 & 53.31 & 804.92 & 701.44 & 12.93 & 36.77 \\
CV & $60 \%$ & $70 \%$ & $174 \%$ & $214 \%$ & $114 \%$ & $104 \%$ & $81 \%$ \\
No. samples $<$ LOD & 5 & - & 2 & 3 & - & 2 & - \\
\hline
\end{tabular}

Table 3 Comparison of average metals loadings in indoor dust $\left(\mu \mathrm{g} / \mathrm{m}^{2}\right)$ in Madrid with other locations

\begin{tabular}{llllllllll}
\hline Location & $\mathrm{Cd}$ & $\mathrm{Cr}$ & $\mathrm{Pb}$ & $\mathrm{Cu}$ & $\mathrm{Zn}$ & $\mathrm{Ni}$ & $\mathrm{Mn}$ & No. of samples & Reference \\
\hline Madrid. Spain & 0.05 & 2.1 & 5.5 & 64 & 142 & 2.9 & 8.3 & 40 & This study \\
Giza. Egypt & 55 & n.a. & 533 & n.a. & n.a. & 88 & n.a. & 8 & Khoder et al. (2010) \\
Canada & 0.8 & 15 & 21 & 35 & 122 & 18 & n.a. & 1025 & Rasmussen et al. (2013) \\
Istanbul. Turkey & 0.06 & 4.3 & 2.2 & 12 & 65 & 20 & 11 & 31 & Kurt-Karakus (2012) \\
Sydney. Australia & 0.34 & 6.5 & 30 & 11 & 51 & 2.1 & 5.9 & 82 & Chattopadhyay et al. (2003) \\
Kwun Tong. China & 3.0 & n.a. & 24 & 63 & 164 & n.a. & 2.6 & 151 & Tong and Lam (2000) \\
Dharan. S. Arabia & 0.11 & 2.4 & 2.0 & 5.8 & 27 & 1.5 & 7.7 & 32 & Turner and Simmonds (2006) \\
Riyadh. S. Arabia & 0.07 & 4.2 & 51 & 7.2 & 32 & 2.6 & n.a. & 20 & Al-rajhl and Madany (1996) \\
Warsaw. Poland & n.a. & 7.3 & 12 & 9.9 & 89 & 3.2 & n.a. & 27 & Lisiewicz et al. (2000) \\
Amman. Jordan & 0.22 & 5.1 & 13 & 10 & 153 & 2.4 & 22 & 20 & Al-Momani (2007) \\
Plymouth. UK & 0.12 & 4.9 & 8.5 & 13 & 44 & 3.5 & 31 & 7 & Turner and Ip (2007) \\
\hline
\end{tabular}

Table 4 Pearson correlation coefficients and significance levels (shaded cells)

\begin{tabular}{|c|c|c|c|c|c|c|c|}
\hline & $\mathrm{Cd}$ & $\mathrm{Cr}$ & $\mathrm{Pb}$ & $\mathrm{Cu}$ & $\mathrm{Zn}$ & $\mathrm{Ni}$ & $\mathrm{Mn}$ \\
\hline $\mathrm{Cd}$ & 1 & $* * *$ & $* *$ & * & & $*$ & $* * * *$ \\
\hline $\mathrm{Cr}$ & 0.67 & 1 & . & $*$ & & & $* *$ \\
\hline $\mathrm{Pb}$ & 0.52 & 0.35 & 1 & & $* * *$ & $* *$ & $* * *$ \\
\hline $\mathrm{Cu}$ & 0.45 & 0.4 & 0.18 & 1 & . & & . \\
\hline $\mathrm{Zn}$ & 0.28 & 0.08 & 0.62 & 0.35 & 1 & $*$ & $*$ \\
\hline $\mathrm{Ni}$ & 0.39 & 0.22 & 0.55 & 0.25 & 0.47 & 1 & $* *$ \\
\hline $\mathrm{Mn}$ & 0.73 & 0.49 & 0.74 & 0.36 & 0.38 & 0.54 & 1 \\
\hline
\end{tabular}

Figure 2 presents the metal loadings found in the entry hall, kitchen, living room, and bedroom. The entry hall was the area with the highest average loadings of $\mathrm{Cd}(0.062 \mu \mathrm{g} /$ $\left.\mathrm{m}^{2}\right), \mathrm{Cr}\left(2.8 \mu \mathrm{g} / \mathrm{m}^{2}\right), \mathrm{Cu}\left(75 \mu \mathrm{g} / \mathrm{m}^{2}\right), \mathrm{Zn}\left(143 \mu \mathrm{g} / \mathrm{m}^{2}\right), \mathrm{Ni}$ $\left(2.7 \mu \mathrm{g} / \mathrm{m}^{2}\right)$, and $\mathrm{Mn}\left(9.5 \mu \mathrm{g} / \mathrm{m}^{2}\right)$. In the case of $\mathrm{Pb}$, the highest mean loadings were found in the kitchen $(2.9 \mu \mathrm{g} /$ $\mathrm{m}^{2}$ ). However, no significant differences between rooms were observed except for $\mathrm{Cu}$ between entry hall and the living room, and for $\mathrm{Cu}$ and $\mathrm{Cr}$ between the entry hall and the kitchen ( $p$ value $<0.05$ ). Figure 2 suggests that house dust metals most likely have a predominant outdoor origin and are tracked indoors adhered to footwear, accumulating preferentially in the entry hall (Hunt et al. 2006). The dust thus introduced in homes can be redistributed between rooms adhered to footwear or by drafts during ventilation. This process together with indoor dust generation can reduce the load differences between rooms, making them not statistically significant.

Stepwise multiple linear regression analysis was performed to assess which of the considered factors (room, presence of smokers of traffic intensity, flat floor, number of residents, and days between cleaning events) has a significant influence in dust metal loadings (Table 5). During the iterative process, the non-statistically significant variables were eliminated. $R$-multiple squared correlation coefficients allow us to evaluate the predictive power of the models generated. The models with greater predictive power are those generated for $\mathrm{Cr}, \mathrm{Zn}$, and $\mathrm{Mn}$. 
Cd

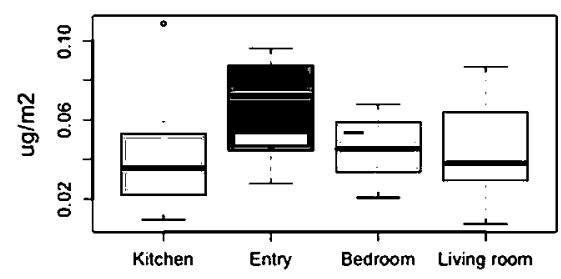

Cu
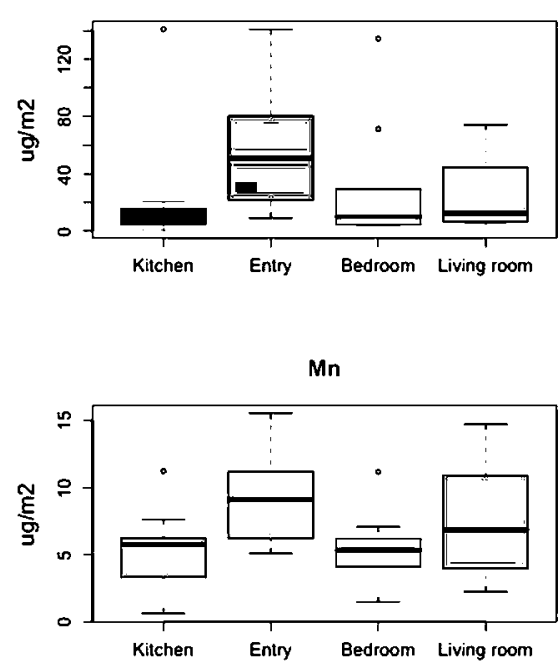

Cr

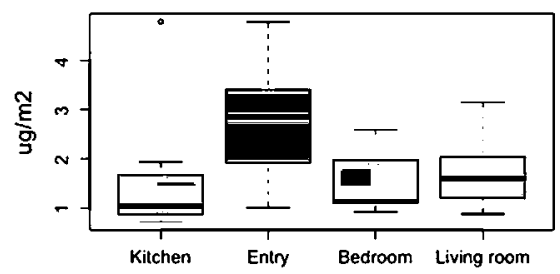

Zn

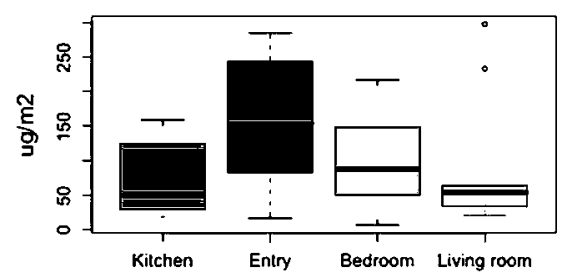

Pb

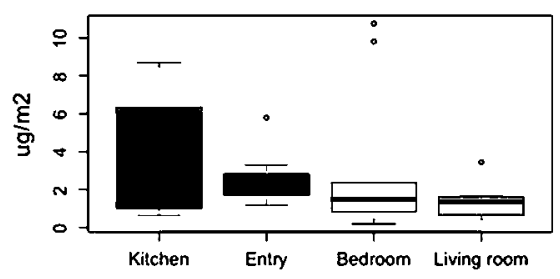

$\mathrm{Ni}$

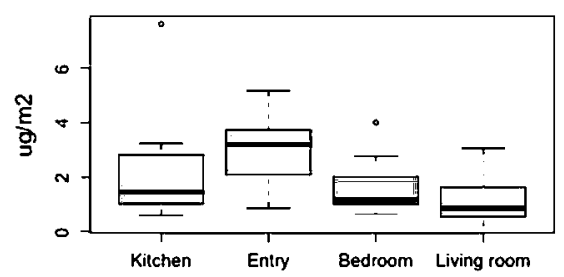

Fig. 2 Distribution of dust metal loadings between rooms

Table 5 Multiple linear regression results

\begin{tabular}{|c|c|c|c|c|c|c|c|}
\hline Ambient factor & $\mathrm{Cd}$ & $\mathrm{Cr}$ & $\mathrm{Pb}$ & $\mathrm{Cu}$ & $\mathrm{Zn}$ & $\mathrm{Ni}$ & Mn \\
\hline (Intercept) & $4.43 E-02$ & $-7.85 \mathrm{E}-01$ & $3.67 \mathrm{E}+00$ & $-1.81 \mathrm{E}+01$ & $2.47 \mathrm{E}+01$ & $-8.16 \mathrm{E}-02$ & $7.16 \mathrm{E}+00$ \\
\hline Room (entry) & $3.35 E-02$ & $1.15 E+00$ & - & - & $8.28 \mathrm{E}+01$ & - & $3.79 \mathrm{E}+00$ \\
\hline Room (bedroom) & $5.83 \mathrm{E}-03$ & $1.75 \mathrm{E}-01$ & - & - & $2.21 \mathrm{E}+01$ & - & $-1.97 \mathrm{E}-01$ \\
\hline Room (living room) & $5.11 \mathrm{E}-03$ & $1.81 \mathrm{E}-01$ & - & - & $2.30 \mathrm{E}+01$ & - & $2.43 E+00$ \\
\hline Traffic intensity & - & $5.29 \mathrm{E}-05$ & - & - & - & - & - \\
\hline Smokers present & $3.36 \mathrm{E}-02$ & $-7.75 \mathrm{E}-01$ & $3.63 \mathrm{E}+00$ & $2.58 \mathrm{E}+01$ & $1.00 \mathrm{E}+02$ & - & $3.26 \mathrm{E}+00$ \\
\hline Number of residents & - & $5.22 \mathrm{E}-01$ & $-9.04 \mathrm{E}-01$ & $1.38 \mathrm{E}+01$ & - & - & - \\
\hline Flat height & - & - & - & - & - & - & $-9.01 E-01$ \\
\hline Number of days between cleaning & - & - & - & - & - & $4.54 \mathrm{E}-01$ & - \\
\hline Multiple $R^{2}$ & $3.30 \mathrm{E}-01$ & $6.35 \mathrm{E}-01$ & $3.94 \mathrm{E}-01$ & $2.46 \mathrm{E}-01$ & $5.12 \mathrm{E}-01$ & $1.42 \mathrm{E}-01$ & $6.25 \mathrm{E}-01$ \\
\hline
\end{tabular}

Statistically significant ( $90 \%$ confidence) coefficients are show in bold case. Excluded explanatory variables are denoted by a dash

Taking into account the effects of the statistically significant variables, the room in which the dust sample has been taken seems to be determinant in the case of $\mathrm{Cd}, \mathrm{Cr}$, $\mathrm{Zn}$, and Mn, suggesting an important outdoor source of dust that enters the homes adhered to footwear.

Traffic intensity was quantified as the number of vehicles per day that drive along the nearest street of each sampled apartment. Despite all the metals included in the study might be associated with traffic (Ball et al. 1998), only $\mathrm{Cr}$ has shown a significant regression coefficient. $\mathrm{Cr}$ is present in various moving engine parts and can be released by brake lining wear.

Floor elevation has been proposed as a factor influencing the metal loadings found in indoor dust (Thatcher and Layton 1995). It would be expected that if the entry of outdoor suspended dust in the apartment through windows 
was significant, all metal loadings would be higher in lower floors. A significant negative regression coefficient between metal loading and apartment elevation was only observed for Mn. It seems that the contribution of this route to the total mass of indoor dust metals is lower than the amount brought indoors adhered to footwear and clothing and the amount generated indoors by residents, particularly smokers.

The presence of smokers was a significant variable in the prediction of most metals. A Tukey's range test (Table 6) revealed higher metal loadings in apartments with the presence of smokers ( 20 samples) than in apartments of non-smoking families, with strongly significant differences for all metals except $\mathrm{Cr}$. It has been reported that the amount of indoor $\mathrm{PM}_{3.5}$ particles increases with the presence of smokers (Wallace 1996), and that so does the amount of metals (Khoder et al. 2010; Rasmussen et al. 2013). Moreover, the metal content in dust has been found to increase with the number of smokers in the house (Wallace 1996). The main sources of metals in cigarettes are tobacco plant, filters, and paper (Chiba and Masironi 1992). The tobacco plant absorbs metals from soil, fertilizers, and pesticides. Their concentration fluctuates depending on stem height and leaf age. Metal particles can also be retained on the leaves during the manufacturing process due to the sticky nature of the tobacco leaves (Yebpella 2011). The amount of each metal in a cigarette depends on the cigarette brand and changes within the same brand (Chiba and Masironi 1992).

The number of residents was significantly correlated with $\mathrm{Cr}, \mathrm{Pb}$, and $\mathrm{Cu}$ dust loads. Lastly, there was a significant regression coefficient between Ni loadings and the number of days without home cleaning. The absence of this dependence for the other trace elements is in agreement with the results of Zota et al. (2011) who did not find any significant differences in metal concentrations in dust between "good," "normal," and "poor" housekeeping.

It must be remarked that the results of the statistical analyses should be interpreted with caution given the not insignificant uncertainty arising from a reduced dataset.

\section{Health Risk Assessment}

The results obtained in the risk assessment are presented in Fig. 3. Exposure to trace elements in indoor dust resulted in acceptable levels of aggregated risk for human health, both carcinogenic (Risk $<10^{-5}$ ) and non-carcinogenic (HQ $<1$ ) through ingestion and dermal contact for all the age groups considered in this study. Regarding the ingestion route, children between 6 and 12 months experienced the highest value of non-carcinogenic risk. At this age, children change their behavioral habits progressively, and are more susceptible to hand-to-mouth activities and accidentally ingest a larger amount of dust. The increasing bodyweight of children between 2 and 6 years of age causes a decrease of the HQ relative to the previous age bracket. Among the elements included in this study, $\mathrm{Cu}$ is the largest contributor to the aggregated non-carcinogenic risk because of its high concentration in indoor dust. In terms of carcinogenic risk, the contribution of $\mathrm{Cr}$ was higher than that of $\mathrm{Pb}$ for both the dermal and the oral exposure routes.

It is worth noting that although the level of non-carcinogenic risk lies below the threshold of unacceptability, the highest HQ value determined in this study is close to 0.2 . Compared with the contribution of other solid matrices (i.e., playground soil (De Miguel et al. 2007), infant food (Llobet et al. 2003), park and garden soil, and locally purchased food (Cao et al. 2016)), contact with indoor dust has a notable impact on the overall risk from exposure to trace elements experienced by children in urban environments.

Although the main results of the risk assessment presented in this work are valid, the numerical results should be interpreted with caution since they are affected by several uncertainty factors. An important source of uncertainty arises from the lack of bioaccessibility data in this study. Bioaccessibility of trace elements in dust is highly variable and it depends, among other factors, on the mineralogy of dust particles, kind and intensity of industrial or traffic emissions, and domestic practices. For example, the gastric bioaccessibility of $\mathrm{Pb}$ has been reported to range from less than 20 to $80 \%$ and that of $\mathrm{Cr}$ can be lower than $10 \%$ (Turner 2011).
Table 6 Results of application of the Tukey's range test to assess the role of the presence of smokers to the log-transformed metal dust loading data

\begin{tabular}{lcclc}
\hline \multicolumn{5}{l}{ Smokers present-smokers absent } \\
\cline { 2 - 5 } & Difference & Lower confidence limit & Upper confidence limit & $p$ value \\
\hline $\mathrm{Cd}$ & 0.65 & 0.26 & 1.04 & $\mathbf{1 . 7 0 E}-\mathbf{0 3}$ \\
$\mathrm{Cr}$ & -0.10 & -0.44 & 0.24 & $5.67 \mathrm{E}-01$ \\
$\mathrm{~Pb}$ & 1.10 & 0.49 & 1.70 & $\mathbf{8 . 1 4 E}-\mathbf{0 4}$ \\
$\mathrm{Cu}$ & 1.16 & 0.31 & 2.01 & $\mathbf{8 . 6 9 E}-\mathbf{0 3}$ \\
$\mathrm{Zn}$ & 1.17 & 0.67 & 1.68 & $\mathbf{3 . 7 7 E}-\mathbf{0 5}$ \\
$\mathrm{Ni}$ & 0.72 & 0.22 & 1.22 & $\mathbf{6 . 0 7 E}-\mathbf{0 3}$ \\
$\mathrm{Mn}$ & 0.63 & 0.22 & 1.03 & $\mathbf{3 . 4 1 E}-\mathbf{0 3}$ \\
\hline
\end{tabular}

Bold $p$ values denote statistically significant differences 

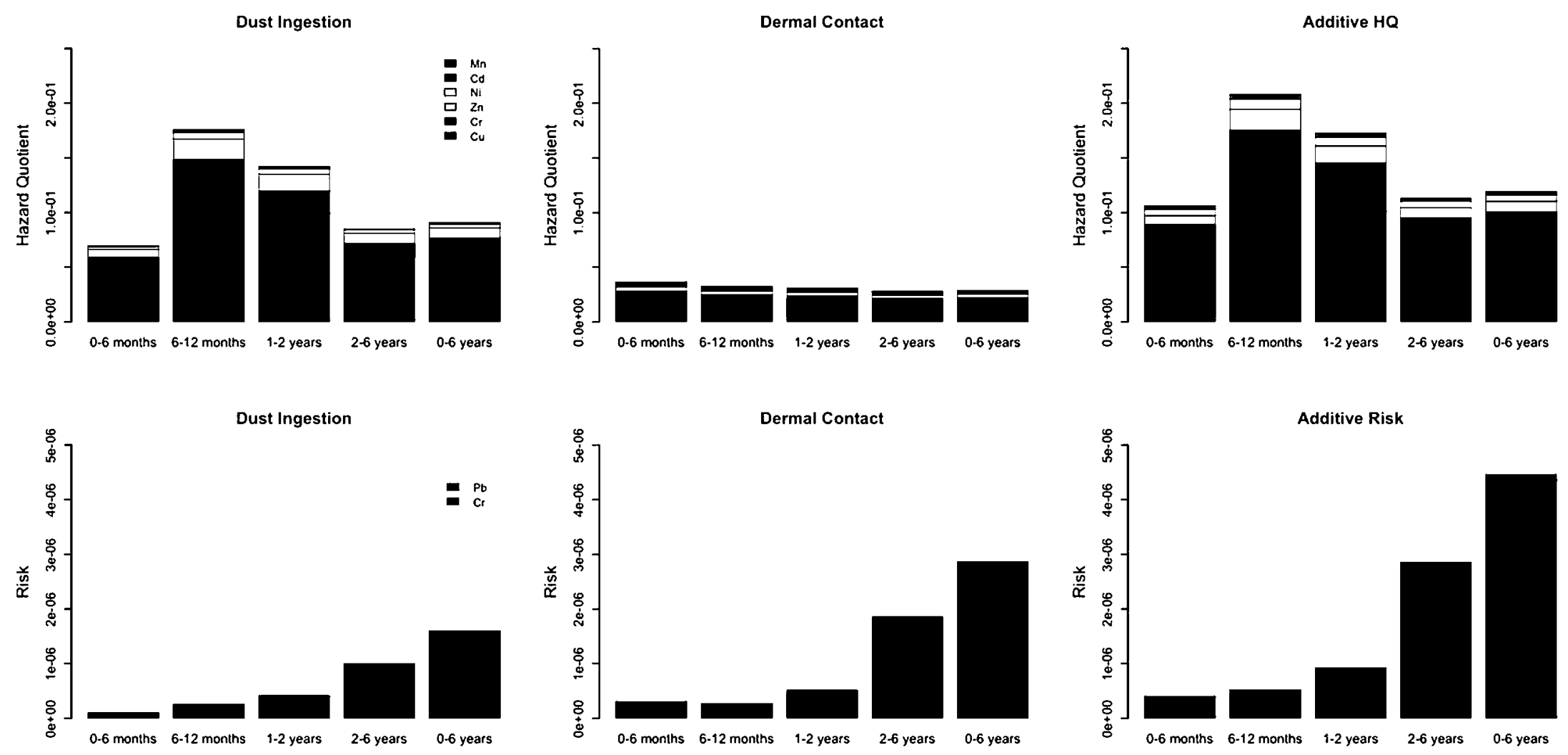

Fig. 3 Hazard quotients (HQ) and cancer risk trough ingestion and dermal absorption 
The use of pseudo-total extractable concentrations in this study is equivalent to the assumption of near-total bioaccessibility, which should result in an overestimation of risk (Ibanez et al. 2010). Applying the mean bioaccessibility values of trace elements in dust obtained by $\mathrm{Hu}$ et al. (2011), the aggregated Hazard Quotients and cancer Risk would decrease by approximately $30 \%$.

A significant uncertainty is also associated with the default value assigned to several exposure variables: dermal absorption factors (ABS) are not available for all metals and a default value of 0.001 has been used as recommended in the Health Risk Assessment Guidance for Metals (ICMM 2007). Other exposure parameters in the risk assessment model have been taken from the U.S. EPA under the uncertain assumption that they are directly applicable to the infant population of Madrid.

Lastly, one of the most important sources of uncertainty is the conversion of metal loadings to concentrations in dust using a dust deposition rate obtained by averaging bibliographic values. Considering the range of variation of bibliographic data, risk estimates associated with dermal contact would increase threefold if the lowest reported deposition rate (Edwards et al. 1998) were used instead of the average, or they would decrease by $64 \%$ if the highest rate (Rasmussen et al. 2013) were selected.

\section{Conclusions}

Trace elements in domestic dust in Madrid seem to present two prevailing origins. They are brought indoors with particles adhered to footwear and clothing (which results in higher metal loadings in the entry hall than in the rest of the apartment) and they arise from indoor sources, most notably tobacco smoking. Apartments of smoking residents present significantly higher loadings of all metals, except Cr. Metal loadings are homogeneously distributed among rooms within each apartment, with $\mathrm{Zn}$ and $\mathrm{Cu}$ presenting the highest loadings of all the metals included in this study. $\mathrm{Cu}$, especially, is found in higher amounts than in other cities where similar studies have been undertaken.

Although the numerical results of the risk assessment are affected by a considerable uncertainty and should be interpreted with caution, one significant conclusion can be drawn: urban children are not expected to develop adverse health effects from exposure to trace elements in household dust alone. However, the contribution of this exposure medium to the overall received dose is far from negligible when compared to other exposure pathways, especially for children between the ages of 6 and 12 months. This result alone should warrant further research in order to reduce the uncertainty associated with the quantitative estimation of risk and to help devise and implement adequate measures of risk mitigation in urban homes.

Acknowledgements The authors thank the reviewers for their comments that have helped increase the quality of this article. This study was funded through the CARESOIL_CM (S2013/MAE-2739) research Grant of the Regional Government of Madrid (Comunidad de Madrid).

\section{References}

AEMET (2014) Meteorological agency of the Spanish State (Agencia Estatal de Metereología). http://www.aemet.es/

Al-Momani IF (2007) Trace elements in street and household dusts in Amman, Jordan. Soil Sediment Contam 16:485-496

Al-rajhl MA, Madany WC (1996) Metal levels in indoor and outdoor dust in Riyadh, Saudi Arabia. Environ Int 22(3):315-324. doi:10. 1016/0160-4120(96)00017-7

Ball JE, Jenks R, Aubourg D (1998) An assessment of the availability of pollutant constituents on road surfaces. Sci Total Environ 209:243-254. doi:10.1016/S0048-9697(97)00319-7

Butte W, Heinzow B (2002) Pollutants in house dust as indicators of indoor contamination. Rev Environ Contam Toxicol 175:1-46

Cao S, Duan X, Zhao X et al (2016) Health risks of children's cumulative and aggregative exposure to metals and metalloids in a typical urban environment in China. Chemosphere 147:404-411. doi: 10.1016/j.chemosphere.2015.12.134

Chattopadhyay G, Lin KCP, Feitz AJ (2003) Household dust metal levels in the Sydney metropolitan area. Environ Res 93:301-307. doi:10.1016/S0013-9351(03)00058-6

Chiba M, Masironi R (1992) Toxic and trace elements in tobacco and tobacco smoke. Bull World Health Organ 70:269-275

De Miguel E, Iribarren I, Chacón E et al (2007) Risk-based evaluation of the exposure of children to trace elements in playgrounds in Madrid (Spain). Chemosphere 66:505-513. doi:10.1016/j.chemo sphere.2006.05.065

DGT (2013) Traffic general direction of the Spanish State (Dirección General de Tráfico). www.dgt.es

Edwards RD, Yurkow EJ, Lioy PJ (1998) Seasonal deposition of housedusts onto household surfaces. Sci Total Environ 224:69-80. doi:10.1016/S0048-9697(98)00348-9

Fergusson JE, Kim ND (1991) Trace elements in street and house dusts: sources and speciation. Sci Total Environ 100:125-150

Glorennec P, Lucas J, Mandin C, Le B (2012) French children' s exposure to metals via ingestion of indoor dust, outdoor playground dust and soil: Contamination data. Environ Int 45:129-134. doi: $10.1016 /$ j.envint.2012.04.010

Hassan SKM (2012) Metal concentrations and distribution in the household, stairs and entryway dust of some Egyptian homes. Atmos Environ 54:207-215. doi:10.1016/j.atmosenv.2012.02.013

Hu X, Zhang Y, Luo J et al (2011) Bioaccessibility and health risk of arsenic, mercury and other metals in urban street dusts from a mega-city, Nanjing, China. Environ Pollut 159:1215-1221. doi:10.1016/j.envpol.2011.01.037

Hunt A, Johnson DL, Griffith DA (2006) Mass transfer of soil indoors by track-in on footwear. Sci Total Environ 370:360-371. doi:10. 1016/j.scitotenv.2006.07.013

Ibanez Y, Le Bot B, Glorennec P (2010) House-dust metal content and bioaccessibility: a review. Eur J Miner 22:629-637. doi:10. 1127/0935-1221/2010/0022-2010

ICMM (2007) HERAG 01: Assessment of Occupational Dermal Exposure and Dermal Absorption for Fact Sheet. 1-49

INE (2014) Instituto Nacional de Estadística. http://www.ine.es 
Khoder MI, Hassan SK, El-Abssawy AA (2010) An evaluation of loading rate of dust, $\mathrm{Pb}, \mathrm{Cd}$, and $\mathrm{Ni}$ and metals mass concentration in the settled surface dust in domestic houses and factors affecting them. Indoor Built Environ 19:391-399. doi:10.1177/1420326X10367284

Kurt-Karakus PB (2012) Determination of heavy metals in indoor dust from Istanbul, Turkey: estimation of the health risk. Environ Int 50:47-55. doi:10.1016/j.envint.2012.09.011

Lioy PJ, Freeman NCG, Millette JR (2002) Dust: a metric for use in residential and building exposure assessment and source characterization. Environ Health Perspect 110:969-983

Lisiewicz M, Heimburger R, Golimowski J (2000) Granulometry and the content of toxic and potentially toxic elements in vacuumcleaner collected, indoor dusts of the city of Warsaw. Sci Total Environ 263:69-78. doi:10.1016/S0048-9697(00)00667-7

Llobet JM, Falcó G, Casas C et al (2003) Concentrations of arsenic, cadmium, mercury, and lead in common foods and estimated daily intake by children, adolescents, adults, and seniors of Catalonia, Spain. J Agric Food Chem 51:838-842. doi:10.1021/jf020734q

Lucas JP, Bellanger L, Le Strat Y et al (2014) Source contributions of lead in residential floor dust and within-home variability of dust lead loading. Sci Total Environ 470-471:768-779. doi:10.1016/ j.scitotenv.2013.10.028

Madrid Council (2013) Tráfico: Información de intensidad media diaria (estudios anuales) 2012 y 2013. http://datos.madrid.es

Mcdonald LT (2010) Wipe sampling methodologies to assess exposures to metals in urban Canadian homes. University of Ottawa

Mcdonald LT, Rasmussen P, Chénier M, Levesque C (2010) Wipe sampling methodologies to assess exposures to lead and cadmium in urban canadian homes. In: Annual international conference on soils, sediments, water and energy

Rasmussen P, Levesque C, Chénier M et al (2013) Canadian House Dust Study: population-based concentrations, loads and loading rates of arsenic, cadmium, chromium, copper, nickel, lead, and zinc inside urban homes. Sci Total Environ 443:520-529. doi:10. 1016/j.scitotenv.2012.11.003

Thatcher TL, Layton DW (1995) Deposition, resuspension, and penetration of particles within a residence. Atmos Environ 29:1487-1497. doi:10.1016/1352-2310(95)00016-R

Tong STY, Lam KC (1998) Are nursery schools and kindergartens safe for our kids? The Hong Kong study. Sci Total Environ 216:217-225. doi:10.1016/S0048-9697(98)00161-2

Tong STY, Lam KC (2000) Home sweet home? A case study of household dust contamination in Hong Kong. Sci Total Environ 256:115-123. doi: 10.1016/S0048-9697(00)00471-X

Turner A (2011) Oral bioaccessibility of trace metals in household dust: a review. Environ Geochem Health 33:331-341. doi:10. 1007/s 10653-011-9386-2

Turner A, Hefzi B (2010) Levels and bioaccessibilities of metals in dusts from an arid environment. Water Air Soil Pollut 210:483-491. doi: 10.1007/s11270-009-0274-7

Turner A, Ip KH (2007) Bioaccessibility of metals in dust from the indoor environment: Application of a physiologically based extraction test. Environ Sci Technol 41:7851-7856. doi:10.1021/ es071194m

Turner A, Simmonds L (2006) Elemental concentrations and metal bioaccessibility in UK household dust. Sci Total Environ 371:74-81. doi: 10.1016/j.scitotenv.2006.08.011

USEPA (1995) Residential sampling for lead: protocols for dust and soil sampling
USEPA (1996a) Analysis of composite wipe samples for lead content Final Report. EPA 747-R-96-003. Office of Prevention, Pesticides, and Toxic Substances. United States Environmental Protection Agency, Washington, DC

USEPA (1996b) Soil screening guidance: technical background document. EPA/540/R95/128. Office of Solid Waste and Emergency Response. United States Environmental Protection Agency, Washington, DC

USEPA (1997) Summary and assessment of published information on determining lead exposures and mitigating lead hazards associated with dust and soil in residential carpets, furniture, and forced air ducts

USEPA (2001) Lead; identification of dangerous levels of lead; final rule

USEPA (2002) Supplemental guidance for developing soil screening levels for superfund sites. OSWER 9355.4-22. Office of Emergency and Remedial Response. United States Environmental Protection Agency, Washington, DC

USEPA (2004) Risk assessment guidance for superfund volume i: human health evaluation manual (Part E, Supplemental Guidance for Dermal Risk Assessment). EPA/540/R/99/005. Office of Solid Waste and Emergency Response. U.S. Environmental Protection Agency, Washington, DC

USEPA (2008) Child-specific exposure factors handbook. EPA/600/ R-06/096F. National Center for Environmental Assessment. United States Environmental Protection Agency, Washington, DC

USEPA (2011) Exposure factors handbook 2011 edition. EPA/600/R09/052F. National Center for Environmental Assessment, Office of Research and Development, U.S. Environmental Protection Agency, Washington, DC

USEPA (2013) ProUCL 5.0. http://www2.epa.gov/land-research/ proucl-software

Wallace L (1996) Indoor particles: a review. J Air Waste Manag Assoc 46:98-126. doi:10.1080/10473289.1996.10467451

Wilson R, Jones-Otazo H, Petrovic S et al (2013) Revisiting dust and soil ingestion rates based on hand-to-mouth transfer. Hum Ecol Risk Assess An Int J 19:158-188. doi:10.1080/10807039.2012. 685807

Wilson R, Mitchell I, Richardson GM (2015) Short communication: estimation of dust ingestion rates in units of surface area per day using a mechanistic hand-to-mouth model. Hum Ecol Risk Assess An Int J. doi:10.1080/10807039.2015.1115956

Yebpella G (2011) Heavy metal content of different brands of cigarettes commonly smoked in nigeria and its toxicological implications. Pac J. 12:356-362

Yiin LM, Rhoads GG, Rich DQ et al (2002) Comparison of techniques to reduce residential lead dust on carpet and upholstery: the New Jersey assessment of cleaning techniques trial. Environ Health Perspect 110:1233-1237. doi:10.1289/ehp. 021101233

Zhu N-Z, Liu L-Y, Ma W-L et al (2015) Polybrominated diphenyl ethers (PBDEs) in the indoor dust in China: levels, spatial distribution and human exposure. Ecotoxicol Environ Saf 111:1-8. doi: 10.1016/j.ecoenv.2014.09.020

Zota AMIRMIR, Schaider LA, Ettinger AS et al (2011) Metal sources and exposures in the homes of young children living near a mining-impacted Superfund site. J Expo Sci Environ Epidemiol 21:495-505. doi: 10.1038/jes.2011.21 